\title{
XL. Account of some optical experiments
}

\section{Samuel Sharpe Esq. F.G.S.}

To cite this article: Samuel Sharpe Esq. F.G.S. (1830) XL. Account of some optical experiments , Philosophical Magazine Series 2, 7:40, 281-284, DOI: 10.1080/14786443008675287

To link to this article: http://dx.doi.org/10.1080/14786443008675287

$$
\text { 曲 Published online: } 13 \text { Jul } 2009 .
$$

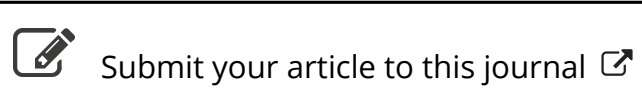

\footnotetext{
Џll Article views: 3
}

Q View related articles $\sqsubset$ 
XL. Account of some Optical Experiments. By Samuer. Sharpe, Esq. F.G.S.*

Expcr. 1.- I HELD a card between my eye and the candle, and moved it gradually till it very nearly hid all the flame, when the edge of the card was tinged with red, and the yellow and blue, \&c. appeared in succession further from the card. The order of the colours proves that the ray of light is (at least principally) refracted round or towards, and not from, the edge + .

Fig. 1. $A$ is a section of the flame,
$B$
of the eye,
C D
of the card;

and R Y V (using three, instead of the seven, for shortness) are the prismatic rays.

The red rays are in excess because of the colour of the flame; and when the card is moved still more towards V, the red is no longer seen, the blue and violet are so pale as to be hardly seen.

By measurement which was not very accurate, the red rays appeared to be refracted about $28^{\prime}$; and my measurement was not accurate enough to determine whether or not different substances refracted light differently. The brightest rays appeared on the card rather than by the side of it, as in fig. 8 , making the fringe described in Experiment 5, and from the cause there mentioned. Part of the inaccuracy of the measurement mentioned above arose from this fringe.

If I applied to the ray a second card B (fig. 9), between the first card $A$ and the candle, and in the same direction, the ray disappeared, being refracted to $\mathbf{C}$.

If I applied it in the contrary direction, as D, no apparent change took place, because, though one ray might be refracted round $D$, there were others to fall on $A$; but when the second card was applied exactly opposite to $A$, as $E$, then the coloured rays were gradually drawn towards $\mathbf{E}$, as it approached.

Exper. 2.- I held before my eye the eye-glass of a telescope having parallel cobwebs in the focus, and moved it before the candle till the light fell obliquely on the cobwebs: the cobweb at $R$ (fig. 1.) was completely red; and as I moved it towards V, the cobwebs were prettily coloured with each of the colours in its turn.

* Communicated by the Author.

+ Newton appears to contradict himself in his Optics and Principia; in one stating that light is refracted round or towards, and in the other from, an intervening edge.

N. S. Vol. 7. No. 40. April $1830 . \quad 2 \mathrm{O} \quad$ This 
This experiment proved the refaction caused by any edge brought near to a ray of light, more clearly and satisfactorily than the former, but did not show whether the ray was refracted from or towards the intercepting edge, as it was not evident on which side of the cobweb the ray passed.

Exper. 3.-I then looked at the candle through a slit between two parallel cards, sometimes $\frac{1}{40}$ th of an inch apart and sometimes less, when the candle appeared, as in fig. 2, very broad, with its edges red; nearer the middle it was yellow, and the middle slightly blue or violet; the red and yellow much in excess, because of the colour of the candle: there was also a row of smaller candles on each side, each of which had its outer edge red, and its inner one violet.

When the cards were further apart, the flame was less distorted, as in fig. 3, with more but narrower traces of side flames: when less apart, more distorted, as in fig. 4, with fewer and wider side flames.

In each case the width of the whole luminous appearance was the same, because the refraction was the same; but the greater the number of rays which passed through the opening, the greater the number of candles into which the coloured rays re-arranged themselves.

Exper. 4.- When I looked at the candle through a round hole in the card of about the same diameter ( $\frac{1}{40}$ th of an inch), the effect was much the same, but less regular in appearance, from its being circular: but when I lessened the hole and came within two feet of the candle (for in the former experiments I had been about ten feet distant), the distinctions of colour were lost, and the hole appeared as in fig. 5 , with a distinct luminous centre, but the outer part was marked with dark rays diverging from that centre.

When I closed the eye-lids a little, the centre remained the same, but parts of the top and bottom of the outer circle were darkened as in fig. 6: when the eyelids were more closed, still more of the top and bottom was darkened, as in fig. 7, plainly proving that light enters the eye through the iris as well as through the pupil; the luminous centre being made by those rays which passed uninterruptedly through the pupil, and the radiated outer circle being the shadow of the iris as thrown on the back of the eye, unless lessened by the intervention of the eyelid, as in figs. 6 and 7.

The bright reflection of a window or candle on the bulb of a thermometer is surrounded by the same radiations, from the same cause.

Exper. 5.-If a card be held so as just to conceal an object, the card will appear fringed with the object, or the object may 
Mr. Sharpe's Account of some Optical Experiments. 283 appear as seen through the edge of the card (see Exper. 1,

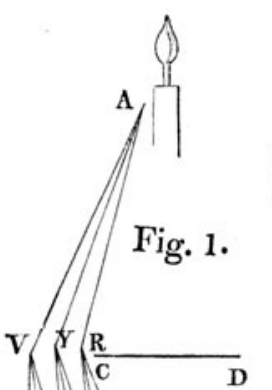

Fig. 2.

$R Y^{R V} Y_{V}$

B the eye

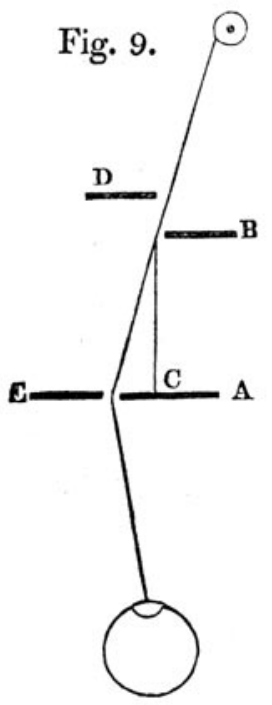

Fig. 10.

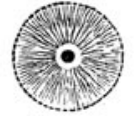

and fig. 8.); and this arises from the pupil not being a point, $2 \mathrm{O}_{2}$

Fig. 4.

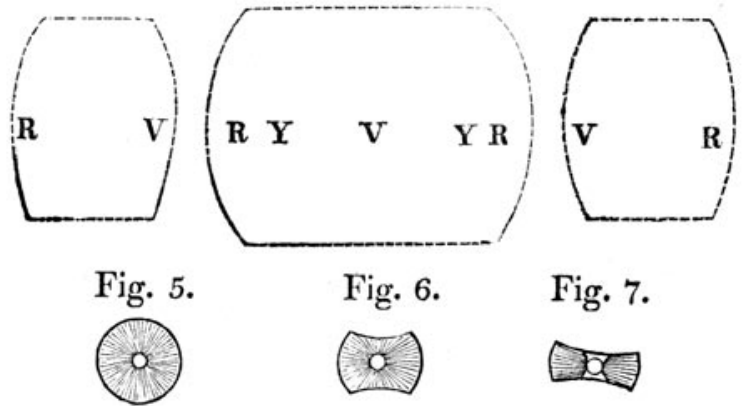

Fig. 11.

Fig. 8 .
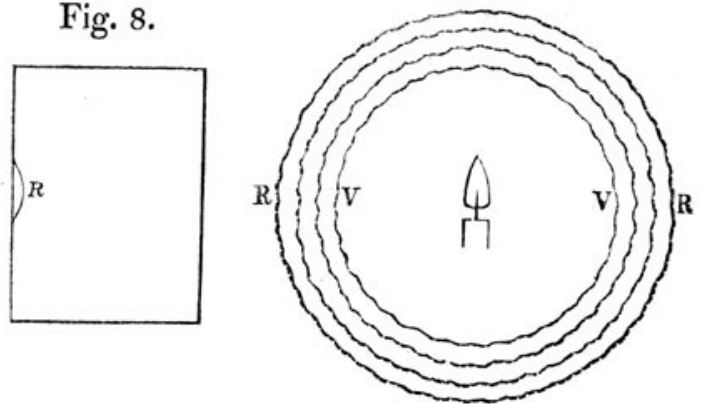

but 


\section{4 \\ Dr. Turner on a Specimen of Varvicite from Ihlefeld.}

but a space of sensible size, and the appearance is the same as when, with two eyes, we hide the candle by a card from one eye only, we may fancy that we see the candle through the card. And from this fringe or indecision of outline arises the slight pain which the eye sometimes feels, on looking at one piece of gauze of fine network through another.

This fringe appears and affects the eye like an object not exactly in the focus of a magnifying glass.

Exper. 6.-If the eye be directed in a piercing manner to an object at six feet distance, with a view to distinguish the minute parts, the lens of the eye is flattened, that is, accommodated to the purpose by having the focus made more distant; if it be then quickly turned to a point of light nine inches distant, there appears a clark spot in the middle, as in fig. 10.

Exper. 7.-If a light be seen through a coach-glass made dull by breath condensed on it, the light appears surrounded by a ring of the prismatic colours, the red being at the outside and the violet at the inner ring. Fig. 11.

Exper. 8.- If the bright spot of light on a thermometerbulb be observed, the outer edge of the spot which enters the eye through the iris, (see fig. 5, 6, 7, 12,) will be seen tinged with red, showing that the eye is not quite achromatic, but is what opticians term under-corrected; but the pupil appears to be perfectly achromatic; though it may perhaps be unphilosophical to apply the term to the pupil; as it is itself our only standard we have no other by which we can compare it.

Canonbury, March 2, 1830.

Samuel Sharpe.

XLI. On a Specimen of Varvicite from Ihlefeld. By Dr. Edward Turner, F.R.S. L.\& E. \&c. Prof. of Chemistry in the University of London. (In a Letter to Richard Phillips, F.R.S. L.\& E.)

My dear Sir,

T HAVE lately received a curious specimen of manganese 1 from Prof. Stromeyer, in the history of which you will feel considerable interest, as my examination of it leaves little or no doubt of its being a specimen of varvicite. It was found about a year ago at Ihlefeld in the Hartz, and occurs in after-crystals having the form of the six-sided pyramid of calcareous spar. From this circumstance it is probable that the crystals at one time consisted of carbonate of manganese, which has been converted into its present state by subsequent decomposition.

Of the nature of the original crystals two views seem plausible. They may originally have been composed of carbonate of 